\title{
To the Budding Women Surgeons: acquire a Rhino's Skin but Retain the Compassion in Heart!
}

\author{
Neharika Neeraj ${ }^{1}$ \\ ${ }^{1}$ Department of Burns, Plastic and Maxillofacial Surgery, Vardhaman \\ Mahavir Medical College and Safdarjung Hospital, New Delhi, India
}

Indian J Plast Surg 2019;52:262

This is in addition to the quintessential "lion's heart, eagle's eye, lady's hands, and horse's leg."

A recent trivial incident made a major realization and an inspiration for this piece: while wetting a plaster of Paris (POP) splint, some dropped onto my feet. The ward staff in attendance perhaps felt that POP on painted toe nails did not seem right. He told me that surgical branches are not really for the ladies. I just smiled because it was like water off a duck's back.

I have noticed that even the most hardworking and efficient women residents during my general surgical residency were trying too hard to prove themselves. In a bid to come across as tough and resilient, I would choose to hold retractors in long surgeries rather than have a bird's eye view of surgery. I was afraid of taking any advantage borne out of sheer good luck too, because I was afraid it would be labeled gender borne.

One day a senior consultant asked me, "Why hold retractors always? Why not see the surgery sometimes?" Fair point. I still am cautious of taking any undue advantage but I have realized that sometimes opportunity comes your way if you are lucky. Any human being, male or female, is entitled to it. I did not see my male colleagues taking the tougher route to prove that they are strong or letting go of any lucky opportunity, be it a good spot during surgery or an off from work. This, plus the consistent confidence of my seniors in me, made me relax.

In full honesty, I did not really face gender bias because both the departments where I underwent training offered
Address for correspondence Neharika Neeraj, MBBS, MS, MCh, DNB, Department of Burns, Plastic and Maxillofacial Surgery, Vardhaman Mahavir Medical College and Safdarjung Hospital, New Delhi 110029, India (e-mail: neharikaneeraj@gmail.com).

great support and encouragement. Perhaps the problem is the biased perception of women surgeons in minds of those who give backhanded compliments along the lines of how you are a good surgeon despite being a woman, rather than any real discrimination. I have heard both men and women coworkers sometimes remark that women are lesser surgeons. But having seen many successful surgeons (both men and women), I have become smarter than to react to this perception.

Patients choose the best surgeon, in their eyes. A man who has chosen to educate his sons and not daughters too will go to a female surgeon if he chose her. Such men are neither looking for muscle nor for beauty; they are looking for skill, confidence, compassion, and reassurance. If they are treated and operated right they will come looking for you, no matter what the general opinion.

For every lame meaningless comment associating gender with surgery, there will be hundreds of times when the patients, male colleagues, and senior teachers totally disregard your gender at you work place, as it should be. Being a good surgeon stays absolutely independent of your gender and it neither puts you at an advantage or disadvantage really. You should neither feel apologetic for working hard and being a tough taskmaster, nor for wearing nail paint. Do your best, rest will fall in place.

\section{Financial Support and Sponsorship \\ Nil.}

\section{Conflicts of Interest}

There are no conflicts of interest. published online

September 18, 2019
DOI https://doi.org/

10.1055/s-0039-1696793 ISSN 0970-0358.
C2019 Association of Plastic Surgeons of India
License terms

(이 (1) $\Theta \circledast$ 